\title{
Commentary
}

\section{$S$-Adenosylhomocysteine: A Better Marker of the Development of Alzheimer's Disease than Homocysteine?}

\author{
Po-Yuan Chang ${ }^{\mathrm{a}}$, Shao-Chun Lu ${ }^{\mathrm{b}}$ and Chu-Huang Chen ${ }^{\mathrm{c}, \mathrm{d}, \mathrm{e}, *}$ \\ ${ }^{a}$ Department of Internal Medicine, National Taiwan University Hospital and National Taiwan University College \\ of Medicine, Taipei, Taiwan \\ ${ }^{\mathrm{b}}$ Department of Biochemistry and Molecular Biology, National Taiwan University College of Medicine, Taipei, \\ Taiwan \\ ${ }^{\mathrm{c}}$ Vascular and Medicinal Research, Texas Heart Institute at St. Luke's Episcopal Hospital, Houston, TX, USA \\ ${ }^{\mathrm{d}}$ Department of Medicine, Baylor College of Medicine, Houston, TX, USA \\ ${ }^{\mathrm{e}}$ Department of Medicine, China Medical University Hospital, Taichung, Taiwan
}

The article by Popp and colleagues [1] highlights the association between the alteration in homocysteine metabolism and Alzheimer's disease (AD) pathology (as reflected by the cerebrospinal fluid biomarkers amyloid- $\beta_{1-42}$ and P-tau181). Moreover, they raise the question as to whether $S$-adenosylhomocysteine (SAH) is a better marker of the development of AD than homocysteine. Although Popp and colleagues [1] found that phosphorylated tau was strongly associated with SAH rather than homocysteine, they did not study the mechanism underlying the SAH-AD association. The data from clinical and epidemiologic studies do not consistently show that plasma levels of homocysteine are associated with an increased risk of cognitive impairment and AD [2-4]. Similarly, clinical trials of vitamin B supplementation as a means of lowering homocysteine levels to prevent cognitive decline in AD patients have not been consistently successful $[5,6]$. Because

* Correspondence to: Chu-Huang Chen, MD, PhD, Vascular and Medicinal Research, Texas Heart Institute, 6770 Bertner Avenue, MC 2-255, Houston, TX 77030, USA. Tel.: +1 832355 9026; E-mail: cchen@heart.thi.tmc.edu. increasing evidence indicates that high plasma levels of homocysteine may not be a marker of vascular injury [6], the finding by Popp and colleagues that SAH, not homocysteine, is associated with tau accumulation in $\mathrm{AD}$ patients is not surprising.

Vascular injury is an essential component underlying both $\mathrm{AD}$ and cognitive impairment in the elderly. The relationship between hyperhomocysteinemia and vascular disease is somewhat controversial. Increasing data suggest $\mathrm{SAH}$ is a better indicator of cardiovascular disease and atherosclerosis than is homocysteine [7,8]. In neurodegenerative diseases, elevated homocysteine levels can lead to higher brain levels of SAH and, in turn, increase phosphorylation of tau [9], supporting the crucial role of SAH in the development of AD. Despite the strong association of increased SAH and tau in AD patients, the molecular mechanisms of SAH-induced neuronal injury (which are most likely vascular) are not clear $[7,8]$. We have recently studied the mechanisms involved in vascular damage induced by homocysteine and SAH [10].

In our study, exposure of human coronary artery endothelial cells to homocysteine alone, even at supra- 
physiologic concentrations $(500 \mu \mathrm{mol} / \mathrm{L})$, did not affect cell integrity, including cell survival, cell cycle transition, and growth factor expression. However, low concentrations $(25 \mu \mathrm{mol} / \mathrm{L})$ of homocysteine induced cytotoxic changes in endothelial cells under culture conditions that increased the intracellular level of SAH [10]. We believe that in the absence of SAH, the vascular effects of homocysteine are negligible, even at the supraphysiologic concentrations used in many in vitro studies.

The critical role of SAH, rather than homocysteine, in inducing damage in vascular endothelial cells may help explain the lack of health benefits observed in several nutritional intervention trials [5], in which vitamin supplementation decreased plasma levels of homocysteine but not SAH. Unlike homocysteine, SAH levels in the plasma are not related to vitamin B6, vitamin B12, or folic acid concentrations [11,12]. Therefore, the SAH-vascular injury-AD axis may be considered one of several mechanisms linking homocysteine metabolism to the development of AD pathology [13-15]. Given the increasing evidence of the detrimental vascular effects of SAH, it would be of considerable interest to see a large-scale, prospective study of the relationship between plasma or cerebrospinal fluid levels of SAH and the development of $\mathrm{AD}$.

\section{ACKNOWLEDGMENTS}

The authors thank Rebecca Bartow, Ph.D., of the Texas Heart Institute at St. Luke's Episcopal Hospital for editorial assistance, and Miss Yi-Jie Chen for technical assistance.

Supported in part by research grant 1-04-RA-13 from the American Diabetes Association; grants NSC 91-2320-B-002-185, 93-2314-B-002-125, 94-2320B-002-121, 95-2320-B-002-116, 98-2628-B-002-088 from the National Science Council, Taiwan; grants NTUH92A14, 93A02, 95S342, 96S643 from National Taiwan University Hospital, Taiwan.

Authors' disclosures available online (http://www.jalz.com/disclosures/view.php?id=360).

\section{REFERENCES}

[1] Popp J, Lewczuk P, Linnebank M, Cvetanovska G, Smulders Y, Kolsch H, Frommann I, Kornhuber J, Maier W, Jessen F (2009) Homocysteine metabolism and cerebrospinal fluid markers for Alzheimer's disease. J Alzheimers Dis 18, 819828.

[2] Blennow K, Hampel H (2003) CSF markers for incipient Alzheimer's disease. Lancet Neurol 27, 605-613.

[3] Seshadri S, Beiser A, Selhub J, Jacques PF, Rosenberg IH, D'Agostino RB, Wilson PW, Wolf PA (2002) Plasma homocysteine as a risk factor for dementia and Alzheimer's disease. $N$ Engl J Med 346, 476-483.

[4] Van Dam F, Van Gool WA (2009) Hyperhomocysteinemia and Alzheimer's disease: A systematic review. Arch Gerontol Geriatr 48, 425-430.

[5] Aisen PS, Schneider LS, Sano M, Diaz-Arrastia R, van Dyck CH, Weiner MF, Bottiglieri T, Jin S, Stokes KT, Thomas RG, Thal LJ; Alzheimer Disease Cooperative Study (2008) High-dose B vitamin supplementation and cognitive decline in Alzheimer disease: a randomized controlled trial. JAMA 300, 1774-1783.

[6] Clarke RJ, Bennett DA (2008) B Vitamins for prevention of cognitive decline: insufficient evidence to justify treatment. JAMA 300, 1819-1821.

[7] Wagner C, Koury MJ (2007) $S$-adenosylhomocysteine: a better indicator of vascular disease than homocysteine? Am J Clin Nutr 86, 1581-1585.

[8] Liu C, Wang Q, Guo H, Xia M, Yuan Q, Hu Y, Zhu H, Hou M, Ma J, Tang Z, Ling W (2008) Plasma S-adenosylhomocysteine is a better biomarker of atherosclerosis than homocysteine in apolipoprotein E-deficient mice fed high dietary methionine. J Nutr 138, 311-315.

[9] Sontag E, Nunbhakdi-Craig V, Sontag JM, Diaz-Arrastia R, Ogris E, Dayal S, Lentz SR, Arning E, Bottiglieri T (2007) Protein phosphatase 2A methyltransferase links homocysteine metabolism with tau and amyloid precursor protein regulation. J Neurosci 27, 2751-2759.

[10] Chang PY, Lu SC, Lee CM, Chen YJ, Dugan TA, Huang WH, Chang SF, Liao WS, Chen CH, Lee YT (2008) Homocysteine inhibits arterial endothelial cell growth through transcriptional downregulation of FGF2 involving G protein and DNA methylation. Circ Res 102, 933-941.

[11] Green TJ, Skeaff CM, McMahon JA, Venn BJ, Williams SM, Devlin AM, Innis SM (2010) Homocysteine-lowering vitamins do not lower plasma S-adenosylhomocysteine in older people with elevated homocysteine concentrations. Br J Nutr 21, 1-6.

[12] Becker A, Smulders YM, Teerlink T, Struys EA, de Meer K, Kostense PJ, Jakobs C, Dekker JM, Nijpels G, Heine RJ, Bouter LM, Stehouwer CD (2003) $S$ adenosylhomocysteine and the ratio of $S$-adenosylmethionine to $S$-adenosylhomocysteine are not related to folate, cobalamin and vitamin B6 concentrations. Eur J Clin Invest 33 17-25.

[13] Vafai SB, Stock JB (2002) Protein phosphatase 2A methylation: a link between elevated plasma homocysteine and Alzheimer's disease. FEBS Lett 518, 1-4.

[14] Nicolia V, Fuso A, Cavallaro RA, Di Luzio A, Scarpa S (2010) $\mathrm{B}$ vitamin deficiency promotes tau phosphorylation through regulation of GSK3beta and PP2A. J Alzheimers Dis 19, 895907.

[15] Chan AY, Alsaraby A, Shea TB (2008) Folate deprivation increases tau phosphorylation by homocysteine-induced calcium influx and by inhibition of phosphatase activity: Alleviation by S-adenosyl methionine. Brain Res 1199, 133-137. 